\title{
"Factors of uneven progress of the European Union countries towards a circular economy"
}

\begin{tabular}{|c|c|}
\hline AUTHORS & $\begin{array}{l}\text { Maxim Polyakov (D) } \\
\mathbb{R} \\
\text { Igor Khanin (D) } \\
\text { Vladimir Bilozubenko (D) } \\
\mathbb{R} \\
\text { Maxim Korneyev (D) } \\
\mathbb{R} \\
\text { Gennadij Shevchenko }\end{array}$ \\
\hline ARTICLE INFO & $\begin{array}{l}\text { Maxim Polyakov, Igor Khanin, Vladimir Bilozubenko, Maxim Korneyev and } \\
\text { Gennadij Shevchenko (2021). Factors of uneven progress of the European Union } \\
\text { countries towards a circular economy. Problems and Perspectives in } \\
\text { Management, 19(3), 332-344. doi:10.21511/ppm.19(3).2021.27 }\end{array}$ \\
\hline DOI & http://dx.doi.org/10.21511/ppm.19(3).2021.27 \\
\hline RELEASED ON & Friday, 17 September 2021 \\
\hline RECEIVED ON & Monday, 28 June 2021 \\
\hline ACCEPTED ON & Thursday, 09 September 2021 \\
\hline LICENSE & $\begin{array}{l}(c) \text { EY } \\
\text { This work is licensed under a Creative Commons Attribution } 4.0 \text { International } \\
\text { License }\end{array}$ \\
\hline JOURNAL & "Problems and Perspectives in Management" \\
\hline ISSN PRINT & $1727-7051$ \\
\hline ISSN ONLINE & $1810-5467$ \\
\hline PUBLISHER & LLC "Consulting Publishing Company "Business Perspectives" \\
\hline FOUNDER & LLC "Consulting Publishing Company "Business Perspectives" \\
\hline$\sigma^{\circ}$ & $\begin{array}{l}\text { ニニ: } \\
\text { ニ }\end{array}$ \\
\hline NUMBER OF REFERENCES & NUMBER OF FIGURES \\
\hline 39 & 5 \\
\hline
\end{tabular}

(C) The author(s) 2021. This publication is an open access article. 


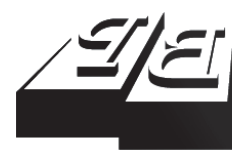

\section{BUSINESS PERSPECTIVES}

O

LLC "CPC "Business Perspectives" Hryhorii Skovoroda lane, 10, Sumy, 40022, Ukraine www.businessperspectives.org
Received on: $28^{\text {th }}$ of June, 2021 Accepted on: $9^{\text {th }}$ of September, 2021 Published on: $17^{\text {th }}$ of September, 2021

(c) Maxim Polyakov, Igor Khanin, Vladimir Bilozubenko, Maxim Korneyev, Gennadij Shevchenko, 2021

Maxim Polyakov, Doctor of Economics, Associate Professor, Noosphere Ventures Inc., USA

Igor Khanin, Doctor of Economics, Professor, National University of Water and Environmental Engineering, Ukraine.

Vladimir Bilozubenko, Doctor of Economics, Professor, University of Customs and Finance, Ukraine.

Maxim Korneyev, Doctor of Economics, Professor, University of Customs and Finance, Ukraine.

Gennadij Shevchenko, Candidate of Technical Sciences, Associate Professor, Association Noosphere, Ukraine.

Maxim Polyakov (USA), Igor Khanin (Ukraine), Vladimir Bilozubenko (Ukraine), Maxim Korneyev (Ukraine), Gennadij Shevchenko (Ukraine)

\title{
FACTORS OF UNEVEN PROGRESS OF THE EUROPEAN UNION COUNTRIES TOWARDS A CIRCULAR ECONOMY
}

\begin{abstract}
The increased final consumption exacerbates the problem of the scarcity of natural resources and leads to environmental pollution. The concept of circular economy, which implies the formation of closed-loop chains of production and consumption with maximum regeneration and recycling of materials, is considered as an alternative to the firmly established "linear economy" (take-make-dispose). As a part of sustainable development strategy, the European Union adopted a general policy on the transition to a circular economy. However, for objective reasons, such transition is quite uneven at the level of member countries, which adversely affects the total progress. Therefore, the need arises to assess the positions of individual countries and identify major reasons for the uneven transition to support the countries that are lagging.

The goal of the study is to identify the factors of uneven progress of the EU countries towards a circular economy. For that reason, a set of empirical data ( 20 indicators) has been compiled; cluster, classification, and parametric analyses have been conducted. As a result, three clusters of the EU countries have been obtained and six indicators, included into combinations that make all clusters different, have been identified. These indicators can be interpreted as the key factors contributing to the uneven progress of the EU countries towards a circular economy. The difference in harmonic means by clusters allowed quantitatively estimating a "circular gap". It is of practical value for the EU policy aimed at bridging the gaps between member countries during the transition to a circular economy.
\end{abstract}

\section{Keywords}

JEL Classification

\section{INTRODUCTION}

Modern capitalism of "unlimited growth" (Valenzuela \& Böhm, 2017) is based on increasing the final consumption, the increase rate of which becomes alarming, that makes the economy more and more unsustainable in terms of the use of primary (fossil) natural resources. Sustaining the traditional "linear economy", described by the take-make-dispose cycle (Ranta et al., 2018), leads to the exacerbation of the problems of resource availability and environment pollution, which blocks further economic development and requires urgent changes of production and consumption models, especially given the climate changes. In the light of the current situation, such models should enable, on one hand, reduction of the volumes and enhancement of the efficiency of the use of natural resources as well as to reduce the level of waste and environmental pollution, and, on the other hand - enable maintaining the achieved population's welfare level in conditions of ever-increasing demands that will ensure sustainability. 
Re-thinking of the linear approach has revived the ideas on resource-saving and waste recycling, which have been developed since the second half of the twentieth century, and, in recent years, they have been formalized at a new level as a concept of circular economy, corresponding to the doctrine of sustainable development. This concept, which is gaining popularity, implies the creation of a closed circular cycle of production and consumption that ensures maximum processing of consumer goods, regeneration, and recycling of materials, the emphasis is laid on the use of the local sources of resources and minimization of the use of primary natural resources. Therefore, a circular economy is a real alternative to unsustainable systems of production and turns into a broad-scale approach, being a basis for the development of corporate strategies and government policy, using new reserves to enhance production efficiency and, at the same time, contributing to the improvement of human health and environmental condition.

Closely adhering to the doctrine of sustainable development, the European Union (EU) supported the transition to a circular economy, which corresponds to its competencies. Ecological and resource agenda required the initiation of the course for building circular economy common for all countries, which was formalized in the form of integral supranational policy. Every EU country, within its capabilities, develops a circular economy; although, for objective reasons, transition to this economy is quite uneven, which adversely affects the total progress. Therefore, this study is aimed to identify the key factors contributing to the unevenness of the progress made by the EU countries towards a circular economy, demonstrating the efficiency of their strategy holding to a common course. This, above all, will enable identifying the areas of support for the countries that are lagging and better coordinate their strategies.

\section{LITERATURE REVIEW}

The term "Circular Economy", focused on the closeness of production-consumption chains, is officially used in the EU (Kern et al., 2020) as well as in the scientific and expert discourse (Kirchherr et al., 2018; Marino \& Pariso, 2020). In general, a circular economy is defined as the economy that reduces consumption of resources and generation of waste as well as recycling and processing of waste in the processes of production, distribution, and consumption (United Nations Environment, 2011). There is created a circular chain (full cycle) of production-supply-consumption-processing with wasteless or low-wasted approach, which enables using resources and manufacture products in the most efficient way, including waste management. This implies a deep transformation of the existing production systems, arrangement of alternative production chains and new models of consumption, introduction of more effective and environmentally sound technologies.

Such type of economy is aimed to replace "linear" model of economic growth and established forms of operation of a wide range of sociotechnical systems, constituting a material basis for the life of modern societies and, in the current context, do not correspond to the increasing requirements for sustainability (Schot \& Kanger, 2018). After the recession triggered by the global economic crisis of 2008-2009, as well as due to the effects of the COVID-19 pandemic, a circular economy became a focus of attention in terms of economic recovery, making it a focus area of the national strategies, taking into consideration new ecological, economic and social requirements, combined by the doctrine of sustainable development (Korhonen et al., 2018a). In the theoretical aspect, the concept of a circular economy often remains fragmentary, and, in the practical aspect, its establishment has significant economic, social, technological, and even environmental limitations. In general, this concept is being actively finalized, and more and more starts to determine the course for the development of production systems, which points out the need to study the specificities of the countries' progress towards circularity.

Circular economy develops an alternative approach, corresponding to the goals and requirements of sustainable development, capable of addressing the challenges of the environmental agen$\mathrm{da}$ and, at the same time, overcoming the economic problems (Geissdoerfer et al., 2017; Schroeder et al., 2018); therefore, it has approval and support of national governments and international organizations, including the EU. On the other hand, a 
circular economy implies enhanced efficiency in the use of resources, increased level of production, optimization of production systems, which provide benefits and make this concept attractive for business (Velenturf \& Purnell, 2021). Under the pressure of escalating problems with fossil resources, environmental pollution, rise in waste generation, climate changes, the concept of circularity is expanding to all sectors of the economy and starts setting the focus areas of transformation: models of production organization, supply chains, forms of services, waste management systems, business models (Korhonen et al., 2018b; Pakurár et al., 2020). Accordingly, reforming the production systems towards sustainability is related to production, processing, logistics, management, which is engulfed in the Fourth Industrial Revolution (Enyoghasi \& Badurdeen, 2021). Circular models are actively introduced in construction, pharmaceutics, textile and apparel industry, chemical and petrochemical industry, electronics and computer production, production of metals, leather, paper, cars, and many other things; ensuring circularity in the sphere of plastic and packaging becomes especially relevant. The need for innovative technologies, materials, models of organization, management systems, logistic systems, etc. opens up new areas for innovations and new spheres for business (Barros et al., 2021). Enterprises should quite quickly change traditional methods of operation and adapt to the requirements for sustainability, achieving the desired levels of efficiency (Geissdoerfer et al., 2020). However, at the same time, it raises multiple technological challenges, institutional barriers, market, and social challenges, and the need for capital emerges. Therefore, it is critical creating favorable conditions for the formation of a circular economy (Grafström \& Aasma, 2021), which underlines the need for support from national governments and international organizations, including the EU. On the other hand, they are also interested in the progress towards such economy, taking into consideration the fact that it has more and more impact on the economic growth on account of creating the added value, recycling of materials, innovative technologies, services, intellectual solutions, trade and productive diversification (Hysa et al., 2020). In this context, at the EU level, there is an interest in the uneven progress made by the countries towards a circular economy in terms of support as well as in terms of the potential of economic growth.
In different countries, especially in Europe, targeted government policies are implemented towards a circular economy. These efforts are being more and more integrated at the international level; therefore, such organizations as the UN and OECD make mowing towards circularity their strategic course, due to the global importance of resource and climate challenges (Velenturf et al., 2019). Owing to the involvement of most countries in the system of natural resource distribution through the world markets and global production chains, the unilateral approaches to the progress towards a circular economy are ineffective. The international cooperation and initiatives of international organizations in the sphere of circularity are being intensified, which is facilitated by the globalization of sustainable development ideas. Even in the context of intensive international trade, a circular economy starts to be considered a regime capable of transforming the global economic model, complementing it with a set of new rules. Therefore, establishing the causes of the uneven progress of the countries towards circular economy becomes necessary as well as more complex.

One of the international organizations, which practically support the transition towards a circular economy, is the EU, whose special role is related to the nature of international integration on the principles of supranationality. The EU regulates, compliments, and coordinates activities of member countries in certain areas. Its fields of competence cover the issues of environment and sustainable development, and circular economy is considered as a focal point of supranational policy, aimed not only to change the quality of domestic economy but also to strengthen the positions of uniting around the world. The EU actively involves all member countries in the general process of transition to a circular economy, developing a single strategy, new principles, and requirements, political challenges, and it also supports transformations institutionally and financially (Lazarevic \& Valve, 2017).

In 2015, the European Commission adopted the First circular economy action plan, which outlined the measures to move forward towards a circular economy to ensure sustainable growth, enhance global competitiveness and create jobs. In 2019, the European Commission adopted "The European Green Deal" as a plan to ensure sustainability and transition towards a climate-friend- 
ly neutral economy, which encompassed a wide range of areas: reduction of air pollution and emissions of greenhouse gases; water resources and soil conservation; development of organic agriculture; restoration of biodiversity; building a new energy system, etc. The Circular Economy Action Plan was adopted in 2020 as the practical implementation of the Green New Deal, aimed to achieve carbon-neutral sustainable, free from toxic substances, and completely closed economy by 2050 . Thereby, the EU created a single strategy for moving towards a sustainable economic system and a set of rules for building a circular economy (Kern et al., 2020). At the supranational level, an integral policy of building a circular economy is being developed, covering a wide range of areas (industry, waste disposal and processing, chemicals, plastic, packaging, resource efficiency, environmental safety, and many others), which is enforced by the legal framework, special and sectoral strategies (Iacovidou \& Gerassimidou, 2018; Matthews et al., 2021; Fidélis et al., 2021; Hughes, 2017). The policy of the transition towards a circular economy is still in its emerging state, it includes varied goals and measures, which are implemented in a differentiated way. This is complicated by the involvement of a relatively large number of countries, which justifies the need for monitoring, assessment of overall progress, and comparison of changes by individual changes. This is needed to develop and improve $\mathrm{EU}$ policies in this sphere, taking into consideration the rapid expansion of its focus areas and challenges (Domenech \& Bahn-Walkowiak, 2019; Hartley et al., 2020; Peiró et al., 2020). This poses a problem of the development of appropriate methods (Friant et al., 2021), drawing attention to the uneven progress of member countries of the alliance towards a circular economy.

Taking circular economy as a basis for the global strategy of sustainable development, the EU is compared with other players worldwide, for example, with China, taking into consideration the interrelatedness of their economic relations. This comparison includes drivers of the transition and understanding of a circular economy as well as assessment of progress and the problems of the relevant transformations. It should be noted that the EU and China, in general, have a common view on the need for a transition towards a circular economy and similar concerns about it; however, an understanding of this economy and, accordingly, its practical foundations vary to some extent: China's view is broader, it embraces the problems of the use of resources, recycling of waste and reduction of pollution level; and the EU's view is narrower and focused, inter alia, on the creation of business opportunities (McDowall \& Geng, 2017). There are also great differences in cultural barriers, institutional and structural specificities of the economy in general (Ranta et al., 2018). This demonstrates the complexities of comparing China's and EU's transition to a circular economy, which do not take place inside this alliance.

Presenting circular economy as a new model of production triggers an active scientific and expert discussion as well as EU-wide analytical challenges, aimed at seeking ways to speed up the transition to it. The EU's priority challenge is to find a "circular gap" between EU countries, covering available indicators of circular economy and dividing the countries into "leaders" and "outsiders" (Krysovatyy et al., 2018). In general, across the EU, there is quite a complex picture of building the circular economy, which is difficult to monitor.

Therefore, there is a need not only to monitor the unevenness of the countries' progress towards a circular economy but also to identify the factors that cause it. At the same time, it is naturally followed by the complexity of this economy, multivariance of its assessment as well as natural economic distinctions of the EU member countries. Thus, the study, which was conducted using the method of principal components, enabled the selection of 13 key indicators and identify three factors that, above all, explain data variability (Androniceanu et al., 2021). The analysis of the factors of the unevenness between the EU countries can be carried out not only at the macro level but also at the micro level, for example, in terms of enterprises. The study found that the amount of firms and investments in R\&D is a critical factor in distinctions between EU countries in terms of small and medium-sized enterprises (Bassi \& Dias, 2019). The priorities to achieve sustainability can be also identified for individual materials, covered by the circular economy (Martins \& Castro, 2019). An important part of an empir- 
ical study of the progress of the EU countries towards a circular economy is to explore the barriers on the way towards such an economy inside the alliance (Kirchherr et al., 2018).

Within the context of this study, the challenge of assessing the degree of the progress of the EU countries towards circular economy arouse much interest, encompassing different types of waste and materials consumed, which enables to identify obstacles and efficiency of national government policies as well as to identify the factors of acceleration (Marino \& Pariso, 2020). A similar challenge is addresses based on the multivariate comparative analysis of the EU countries based on the assessment of the levels of circular economy introduction, which enables to identify their distinctive features, gaps between countries and, accordingly, to assess total progress (Zielińska, 2019). The state of circular economy in a country is demonstrated by several special economic, social, and environmental indicators, which enable the creation of a single system of empirical data to assess the degree of the country's transition or progress towards such an economy. The summary of different indicators enables the calculation of a composite index which is useful in complex diagnostics of the current situation and identification of leaders and outsiders in building the circular economy, which can be used by national and European authorities to determine the outcomes and justify the areas of support to accelerate the EU transition to the closed cycle (Momete, 2020).

While recognizing the approaches presented, it should be noted that it is not always that they give a full picture. Due to the complexity of the circular economy, in respect of a large number of EU countries, having major differences, the international comparisons in this sphere are quite difficult and imply multivariate analysis, which is also related to the assessment of a "circular gap". Different integral indices enable to carry out a complex comparison of countries to a certain degree, but they do not make it possible to assess the structure and, above all, to identify the factors of the uneven progress of the countries towards a circular economy. This problem remains unresolved, in particular, in terms of the identification of the countries-leaders and outsiders as well as the qualitative assessment of a "circular gap". Such assess- ments are needed to set the goals, plan initiatives to support countries, justify the areas for overcoming the distinctions between the countries.

\section{AIM AND METHODS}

The study is aimed to identify the factors of uneven progress of the EU countries towards circular economy using Data Mining methods based on the analysis of empirical data.

The assessment of the progress in moving forward towards a circular economy in the EU countries is statistically monitored by special indicators used by Eurostat, which forms the empirical base of this study. The identification of the factors, causing uneven progress of the EU member countries towards such economy, is expected to be implemented in three stages of analysis: first - clustering of the countries by the indicators of a circular economy; second - classification of the obtained clusters of the countries with the identification of the indicators, which have the greatest influence on dividing into these clusters, and, accordingly, can be considered as the factors of the countries unevenness; third - parametric assessment of the level of the uneven progress of the countries towards a circular economy ("circular gap") between the clusters of the EU countries according to the group of indicators which were identified in the course of classification.

The official data of the circular economy by countries, provided by Eurostat, is divided into three columns: 1) waste generation; 2) waste recycling; 3) trade-in recyclable materials (Table 1).

Therefore, it forms a multidimensional set of empirical data on the assessment of the progress made by the countries towards a circular economy. The selected indicators are heterogeneous, specific and enable to cover different aspects of the development of a circular economy. The nature of the relationships between these indicators and their reciprocal influence (interdependence) is not taken into consideration. The equality and equal significance of all indicators are taken as a basis. There are no duplicating and mutually exclusive indicators, however, their different focus should be taken into consideration: the indicators of waste generation 
Table 1. List of the key indicators of circular economy in the EU member countries

\begin{tabular}{|c|c|c|}
\hline \multicolumn{3}{|c|}{ Source: Eurostat Database (2021) } \\
\hline Indicators of circular economy & Year & Variable \\
\hline \multicolumn{3}{|l|}{ Waste production } \\
\hline Generation of municipal waste per capita ${ }^{1}$, kilograms per capita & 2019 & $\mathrm{x}_{1}$ \\
\hline $\begin{array}{l}\text { Generation of waste excluding major mineral wastes per GDP unit, kilograms per thousand euro, chain-linked } \\
\text { volumes (2010) }\end{array}$ & 2018 & $x_{2}$ \\
\hline Generation of waste excluding major mineral wastes per domestic material consumption, \% & 2018 & $x_{3}$ \\
\hline \multicolumn{3}{|l|}{ Waste management } \\
\hline Recycling rate of municipal waste ${ }^{2}, \%$ & 2019 & $\mathrm{x}_{4}$ \\
\hline Recovery rate of construction and demolition waste, $\%$ of construction and demolition mineral waste recycled & 2018 & $x_{5}$ \\
\hline Recycling of biowaste ${ }^{3}$, kilograms per capita & 2019 & $x_{6}$ \\
\hline Recycling rate of e-waste $4, \%$ & 2018 & $x_{7}$ \\
\hline Recycling rate of packaging waste ${ }^{5}, \%$ & 2018 & $\mathrm{x}_{8}$ \\
\hline Recycling rate of packaging waste by type of packaging 5 (Paper and cardboard packaging), $\%$ & 2018 & $x_{9}$ \\
\hline Recycling rate of packaging waste by type of packaging (Plastic packaging), $\%$ & 2018 & $\mathrm{x}_{10}$ \\
\hline Recycling rate of packaging waste by type of packaging ${ }^{5}$ (Wooden packaging), $\%$ & 2018 & $\mathrm{x}_{11}$ \\
\hline Recycling rate of packaging waste by type of packaging (Metallic packaging), $\%$ & 2018 & $x_{12}$ \\
\hline Recycling rate of packaging waste by type of packaging ${ }^{5}$ (Glass packaging), $\%$ & 2018 & $\mathrm{x}_{13}$ \\
\hline \multicolumn{3}{|l|}{ Trade-in secondary raw materials } \\
\hline Trade-in recyclable raw materials, tonne (Imports extra-EU27 from 2020) & 2020 & $\mathrm{x}_{14}$ \\
\hline Trade-in recyclable raw materials, tonne (Exports extra-EU27 from 2020) & 2020 & $x_{15}$ \\
\hline Trade-in recyclable raw materials, tonne (Imports intra-EU27 from 2020) & 2020 & $\mathrm{x}_{16}$ \\
\hline Trade-in recyclable raw materials, tonne (Imports extra-EU28 2013-2020) & 2019 & $x_{17}$ \\
\hline Trade-in recyclable raw materials, tonne (Exports extra-EU28 from 2013-2020) & 2019 & $\mathrm{x}_{18}$ \\
\hline Trade-in recyclable raw materials, tonne (Imports intra-EU28 2013-2020) & 2019 & $\mathrm{X}_{19}$ \\
\hline Circular material use rate, $\%$ of total material use & 2019 & $x_{20}$ \\
\hline
\end{tabular}

Note: Table 1 includes only the indicators for which complete data was provided complete data on all EU countries. Data for Bulgaria and Ireland: $x_{1}, x_{4}, x_{6}-2018$. Data for Cyprus: $x_{7}-2017$. Data for Romania: $x_{7}-2016$. Data for Italy: $x_{7}-2015$. Data for Malta, Netherlands and Slovenia: $x_{8^{\prime}} x_{g^{\prime}} x_{10^{\prime}} x_{11^{\prime}} x_{12^{\prime}} x_{13}-2017$.

should be minimized, the indicators of waste recycling - maximized, and the indicators of trade in recyclable materials do not reach saturation or minimum requirement. Despite this fact, the proposed set of indicators can be used to achieve the aim of this paper, as far as: waste generation is assessed by relative indicators. In general, the indicators are varied, consistent, and generally sufficient for the description of the features of objects (countries); therefore, they can be used to assess the level of the unevenness of the progress of the EU countries towards a circular economy.

At the first stage, it is expected to cluster the EU member countries by the indicators of circular economy, which is based on the set of empirical data of official statistics (Table 1). This set, in fact, is an "object-feature" table, where the EU countries are the objects and the features are represented by the indicators (in Data Mining - features), which are assessed using the data on them. Given the specific nature of the dataset, the generally accepted $k$-means (metrics - Euclidian) algorithm is selected to cluster the EU countries, which is effective provided that data forms compact groups, significantly different from each other (Everitt et al., 2011). Data should be generalized. Clustering was implemented using the software implementation of k-means algorithm, available on the science web portal ScienceHunter (n.d.).

To obtain correct results before applying the algorithm of clustering, it is necessary to verify the quality of data and determine the optimal number of clusters. The verification of data quality is carried out based on three-dimensional visualization, which is built using the method of principal components and multidimensional scaling, 
which enables, with some allowed deviations, to maintain basic structural relations between the objects from different clusters. The optimal number of clusters is determined based on the calculation of special calculation criteria (The sum of squared errors index, The trace index, The Dunn index, The Davies and Bouldin index, CalinskiHarabasz index, PBM index) (ScienceHunter, n.d.).

Every cluster is formed in such a way that the objects, which are included in it, would be the most similar to each other and different from the objects, which are included in other clusters. As a result, a certain characterization of the object takes place by the way of its attribution to a certain cluster (including the objects, which are the most similar to this one). The general ranking of the EU countries is in aggregate by 20 indicators, presented in Table 1; they are divided into clusters, which demonstrates their distinction ("remoteness") and enables to further compare them for the homogeneous groups (for classification and parametric analysis). Clustering, firstly, demonstrates the general structure of data on the totality of objects (countries), which can evidence the availability of unevenness ("circular gap"). Secondly, based on the comparison of countries, it enables to identify the groups of the countries, which are the leaders in moving forward towards a circular economy, and, accordingly, those that are lagging.

At the second stage, it is expected to classify the obtained clusters (classes) in order to identify a limited group of the indicators, which separate the clusters most of all and, therefore, can be considered as the factors of the uneven progress of the EU countries towards a circular economy. The classification will be carried out based on the mathematical processing of data using the logical combinatorial method "decision trees" (Vasylenko \& Shevchenko, 1979), because it enables the identification of relatively small combinations of features with maximum (absolute, if possible) capability to distinguish (information value), pointing out the most significant distinctions between clusters and, accordingly, between the countries included in these clusters. These combinations, based on the core of classification problems in Data Mining, are called "informa- tive groups of features" (IGF). The classification is based on the training dataset (TD), presented in the form of a data table (Table 1), taking into account the countries break down into classes, obtained as a result of clustering. Before classification processing, the quality of TD is verified to identify its maximum information value. The assessment of the information value of TD and every indicator that it contains and further identification of IGF are carried out based on the relevant tools, available on ScienceHunter web portal. The information value of IGF is determined by the following formula:

$$
V\left(x_{i 1}, \ldots, x_{i j}\right)=\frac{1}{k} \sum_{\Delta \in \Gamma} \max _{Y}\left(\frac{m_{\Delta Y}}{m_{Y}}\right),
$$

where $k$ is the number of classes (clusters), $m_{Y}$ is the number of objects belonging to class (cluster) $Y, \Delta=t_{i 1}, t_{i 2}, \ldots, t_{i j}\left(0 \leq t_{i j} \leq k_{i j}-1\right), j=1, \ldots, \Gamma$ means the arbitrary set of parameter values $x_{i 1}, \ldots, x_{i j}(1 \leq \Gamma \leq n), m_{\Delta Y}$ denotes the number of sampling sets of the $m$ class, for which the relation $x_{i j}=t_{i j}(j=1, \ldots, \Gamma)$ is performed, $t_{i j}$ are the values of parameters $x_{i j}$ in the set of $\Delta, \Gamma$ means variety of all sets of parameter values $x_{i 1}, \ldots, x_{i j}$. In case of complete difference (separation) of the classes, this assessment takes the limit value equal to 1 . It should be noted that this assessment is calculated directly using the data of TD.

Individual indicator, included in IGF, can be considered as the factors, causing the uneven progress of the EU member countries towards a circular economy. The combinations of indicators, having an absolute capability to distinguish (information value equal to $100 \%$ ) are, of course, of particular interest. If a few of such IGF are identified, then one combination can be selected or a few combinations can be used in parallel. According to the aim of this paper, the indicators, included in a few of such combinations, can be consolidated, which will enable the identification of a combination of factors of the uneven progress of the EU countries towards a circular economy.

At the third stage, it is expected to carry out a parametric assessment of the level of uneven progress towards a circular economy ("circular gap") between the clusters of the EU countries by the group of indicators, derived from IGF, obtained 
as a result of classification. This parametric assessment includes the calculation of the maximum, harmonic mean, and minimum value of every cluster. "Circular gap" will be calculated as the difference between the corresponding values of different clusters.

\section{RESULTS}

The analysis at the first stage resulted in dividing the EU countries by clusters according to the set of indicators of circular economy (Table 1). According to the above-described methodology of the study, the quality of data was assessed and the optimal number of clusters was identified, which made three clusters. Table 2 shows the clusters of the EU countries, obtained as a result of calculations.

Table 2. Clusters of the EU member countries according to the circular economy development indicators

\begin{tabular}{|c|c|}
\hline Clusters & EU countries \\
\hline Cluster I & Belgium, Germany, Spain, Italy, Netherlands. \\
\hline Cluster II & $\begin{array}{l}\text { Denmark, Ireland, France, Luxembourg, Austria, } \\
\text { Slovenia, Finland, Sweden. }\end{array}$ \\
\hline Cluster III & $\begin{array}{l}\text { Bulgaria, Czech Republic, Estonia, Greece, Croatia, } \\
\text { Cyprus, Latvia, Lithuania, Hungary, Malta, Poland, } \\
\text { Portugal, Romania, Slovakia. }\end{array}$ \\
\hline
\end{tabular}

Dividing into clusters, firstly, demonstrates structural inhomogeneity of this group of countries according to the indicators of circular economy, and, secondly, it is a part of the comparative analysis, which assess the level of the progress towards a circular economy by the individual country versus other countries by the way of its attributing to a certain cluster.

The analysis at the second stage resulted in the identification of the group of indicators, which separate the obtained clusters of countries most of all. The assessment of the quality of obtained TD, which was carried out, found that its information value was $100 \%$. The maximum number of the features is determined as equal to four. As a result of the classification processing, two combinations of indicators (IGF) were obtained with absolute information value, which separated all clusters of countries most of all (Table 3).
Table 3. Combinations of circular economy indicators, which absolutely separate the clusters of the EU countries

\begin{tabular}{|c|c|c|c|c|c|}
\hline \multirow{2}{*}{$\begin{array}{c}\text { Combinations } \\
1\end{array}$} & \multicolumn{4}{|c|}{$\begin{array}{l}\text { Combinations with } \\
\text { maximum information } \\
\text { value* }\end{array}$} & \multirow{2}{*}{$\begin{array}{c}\begin{array}{c}\text { Information } \\
\text { value }\end{array} \\
100 \%\end{array}$} \\
\hline & $x_{3}$ & $x_{4}$ & $x_{5}$ & $x_{13}$ & \\
\hline 2 & $x_{5}$ & $x_{10}$ & $x_{13}$ & $x_{20}$ & $100 \%$ \\
\hline
\end{tabular}

Note: $*_{x}-$ Generation of waste excluding major mineral wastes per domestic material consumption, $\% ; x_{4}-$ Recycling rate of municipal waste (Bulgaria, Ireland - 2018), \%; $x_{5}$ - Recovery rate of construction and demolition waste, $\%$ of construction and demolition mineral waste recycled; $x_{10}$ - Recycling rate of packaging waste by type of packaging (Plastic packaging) (Malta, Netherlands, Slovenia - 2017), \%; $x_{13}$ - Recycling rate of packaging waste by type of packaging (Glass packaging) (Malta, Netherlands, Slovenia - 2017), \%; $x_{20}$ - Circular material use rate, $\%$ of total material use.

The obtained combinations of IGF include the indicators that can be interpreted as the factors of the uneven progress of the EU countries towards a circular economy. After the generalization of the indicators of both combinations and exclusion of duplicates, the general group of key factors was obtained $\left(x_{3}, x_{4}, x_{5}, x_{10}, x_{13}, x_{20}\right)$.

The analysis at the third stage resulted in the calculation of maximum ( $\max$ ), harmonic mean $(\mathrm{hm})$, and minimum $(\mathrm{min})$ values, selected as a result of classifying the indicators by every cluster of the EU countries (Table 4).

Therefore, the factors were identified $\left(x_{3}-\right.$ Generation of waste excluding major mineral wastes per domestic material consumption, $\% ; x_{4}-$ Recycling rate of municipal waste, $\% ; x_{5}$ - Recovery rate of construction and demolition waste, $\%$ of construction and demolition mineral waste recycled; $x_{10}$ - Recycling rate of packaging waste by type of packaging (Plastic packaging), \%; $x_{13}$ - Recycling rate of packaging waste by type of packaging (Glass packaging), $\% ; x_{20}$ - Circular material use rate, $\%$ of total material use), contributing to the uneven progress of the EU countries towards a circular economy, that is important to be kept in mind in the context of the overall strategy for moving forward towards sustainable development. The selected indicators represent the architecture of the leadership of one or another country, which is a focus area for supranational policy, especially in terms of overcoming the "circular gap". To 
Table 4. Results of parametric analysis by the indicators included in the combinations, which separate the clusters of the EU countries

\begin{tabular}{|c|c|c|c|c|c|c|}
\hline \multirow{2}{*}{ EU countries } & \multicolumn{6}{|c|}{ Indicators, included in the combinations of IGF* } \\
\hline & $x_{3}$ & $\mathbf{x}_{4}$ & $x_{5}$ & $x_{10}$ & $x_{13}$ & $x_{20}$ \\
\hline \multicolumn{7}{|c|}{ Cluster I (countries-leaders) } \\
\hline Belgium & 26.4 & 54.7 & 97 & 42.4 & 100 & 24 \\
\hline Germany & 12.1 & 66.7 & 93 & 46.4 & 83 & 12.2 \\
\hline Spain & 16.4 & 34.7 & 75 & 50.7 & 76.8 & 10.2 \\
\hline Italy & 22.9 & 51.3 & 98 & 43.8 & 73.4 & 19.3 \\
\hline Netherlands & 27.9 & 56.9 & 100 & 50.4 & 86.2 & 28.5 \\
\hline $\max$ & 27.9 & 66.7 & 100 & 50.7 & 100 & 28.5 \\
\hline$h m$ & 19.16 & 50.42 & 91.58 & 46.50 & 82.93 & 16.20 \\
\hline $\min$ & 12.1 & 34.7 & 75 & 42.4 & 73.4 & 10.2 \\
\hline \multicolumn{7}{|c|}{ Cluster II (countries-followers) } \\
\hline Denmark & 7.4 & 51.5 & 97 & 31.5 & 84.7 & 7.8 \\
\hline Ireland & 6.6 & 37.6 & 100 & 31 & 82.2 & 1.6 \\
\hline France & 13 & 46.3 & 73 & 26.9 & 76.2 & 20.1 \\
\hline Luxembourg & 10 & 48.9 & 98 & 32.3 & 98.3 & 11.9 \\
\hline Austria & 9.9 & 58.2 & 90 & 31.9 & 83.9 & 11.5 \\
\hline Slovenia & 10.3 & 59.2 & 98 & 60.4 & 98.5 & 10.4 \\
\hline Finland & 7.4 & 43.5 & 74 & 31.1 & 99.3 & 6.2 \\
\hline Sweden & 8.7 & 46.6 & 90 & 50 & 92.7 & 7 \\
\hline $\max$ & 13 & 59.2 & 100 & 60.4 & 99.3 & 20.1 \\
\hline$h m$ & 8.77 & 48.02 & 88.74 & 34.45 & 88.69 & 5.82 \\
\hline $\min$ & 6.6 & 37.6 & 73 & 26.9 & 76.2 & 1.6 \\
\hline \multicolumn{7}{|c|}{ Cluster III (countries-outsiders) } \\
\hline Bulgaria & 15.2 & 31.5 & 24 & 59.2 & 77.6 & 2.4 \\
\hline Czech Republic & 8 & 33.3 & 92 & 57 & 74.8 & 8.3 \\
\hline Estonia & 29.7 & 30.8 & 95 & 37.7 & 65,4 & 15.1 \\
\hline Greece & 13.3 & 21 & 97 & 41.4 & 36 & 4.2 \\
\hline Croatia & 8.8 & 30.2 & 78 & 37.3 & 60.5 & 4.9 \\
\hline Cyprus & 5.2 & 15 & 64 & 54.3 & 46.3 & 2.9 \\
\hline Latvia & 4.8 & 41 & 97 & 35.8 & 68.8 & 4.7 \\
\hline Lithuania & 7.9 & 49.4 & 99 & 69.3 & 58.2 & 4 \\
\hline Hungary & 7 & 35.9 & 99 & 30 & 35.3 & 6.8 \\
\hline Malta & 8.4 & 8.9 & 100 & 19.2 & 28.6 & 7.1 \\
\hline Poland & 10.9 & 34.1 & 84 & 35.7 & 61.8 & 9.8 \\
\hline Portugal & 8.1 & 28.9 & 93 & 33.9 & 51.3 & 2.2 \\
\hline Romania & 4.8 & 11.5 & 74 & 43 & 61.1 & 1.5 \\
\hline Slovakia & 11.7 & 38.5 & 51 & 51.4 & 68.6 & 6.1 \\
\hline Max & 29.7 & 49.4 & 100 & 69.3 & 77.6 & 15.1 \\
\hline $\mathrm{Hm}$ & 8.18 & 23.20 & 70.67 & 39.07 & 52.03 & 3.97 \\
\hline Min & 4.8 & 8.9 & 24 & 19.2 & 28.6 & 1.5 \\
\hline
\end{tabular}

Note: ${ }^{*} x_{3}$ - Generation of waste excluding major mineral wastes per domestic material consumption, $\% ; x_{4}-$ Recycling rate of municipal waste (Bulgaria, Ireland - 2018), \%; $x_{5}$ - Recovery rate of construction and demolition waste, $\%$ of construction and demolition mineral waste recycled; $x_{10}$ - Recycling rate of packaging waste by type of packaging (Plastic packaging) (Malta, Netherlands, Slovenia - 2017), \%; $x_{13}^{10}$ - Recycling rate of packaging waste by type of packaging (Glass packaging) (Malta, Netherlands, Slovenia - 2017), \%; $x_{20}$ - Circular material use rate, $\%$ of total material use. 
Table 5. Difference between the harmonic mean of the indicators, included in the combinations of IGF, as an assessment of "circular gap" between the clusters of the EU countries*

\begin{tabular}{l|c|c|c|c|c|c}
\hline \multirow{2}{*}{$\begin{array}{c}\text { "Circular gap" between } \\
\text { clusters }\end{array}$} & \multicolumn{5}{c}{ Indicators, included in the combinations of IGF* } \\
\cline { 2 - 6 } & $\mathbf{x}_{\mathbf{3}}$ & $\mathbf{x}_{\mathbf{4}}$ & $\mathbf{x}_{\mathbf{5}}$ & $\mathbf{x}_{\mathbf{1 0}}$ & $\mathbf{x}_{\mathbf{1 3}}$ & $\mathbf{x}_{\mathbf{2 0}}$ \\
\hline Clusters "I-II": & 10.39 & 2.4 & 2.84 & 12.05 & -5.76 & 10.38 \\
\hline Clusters "I-III": & 10.98 & 27.22 & 20.91 & 7.43 & 30.9 & 12.23 \\
\hline Clusters "II-III": & 0.59 & 24.82 & 18.07 & -4.62 & 36.66 & 1.85 \\
\hline
\end{tabular}

Note: ${ }^{*} x_{3}$ - Generation of waste excluding major mineral wastes per domestic material consumption, \%; $x_{4}-$ Recycling rate of municipal waste (Bulgaria, Ireland - 2018), \%; $x_{5}$ - Recovery rate of construction and demolition waste, \% of construction and demolition mineral waste recycled; $x_{10}$ - Recycling rate of packaging waste by type of packaging (Plastic packaging) (Malta, Netherlands, Slovenia - 2017), \%; $x_{13}$ - Recycling rate of packaging waste by type of packaging (Glass packaging) (Malta, Netherlands, Slovenia - 2017), \%; $x_{20}$ - Circular material use rate, $\%$ of total material use.

improve the rankings of the countries from clusters II and III, aspiring to move to a higher cluster, an increase of exactly these indicators should be a priority, which will enhance the efficiency of management on account of the rational concentration of resources.

Table 5 shows the assessment of a "circular gap" between the clusters based on the calculation of the difference between harmonic mean values of the obtained indicators by clusters.

Negative values $x_{10}$ (clusters II-III) и $x_{13}$ (clusters I-II) demonstrate the ambiguity in clustering. However, in general, the difference between the harmonic mean of the indicators demonstrates the level of the unevenness of the indicators of a circular economy by the previously identified clusters of the EU countries, i.e., "circular gap".

\section{DISCUSSION}

The outcomes of the first stage are the breakdown of the EU countries into clusters, which can be used: 1) in the preparation of analytical reports on the progress of the EU countries towards a circular economy; 2) to justify the differentiated support to the countries, adapting the relevant EU programs to the specificity of the individual groups of countries (leaders, followers, and outsiders), which enables to take "targeted" support measures. This will facilitate the integrity and cooperation of similar countries. Within this context, the clustering of countries by the indicators of circular economy complements the studies in the sphere of international trade (geographic structure of trade in waste, scrap, recycled materials, and several other goods). The clustering, demonstrating the "landscape" of circular economy in the EU, is helpful to identify "growth poles" of such economy; therefore, it will be useful for justifying the location of different areas for the development of relevant technologies and building of new production systems.

The outcomes of the second stage are the identification of the indicators among all of them, represented as the factors of the unevenness of the progress made by the EU countries towards a circular economy. This is valuable to management aimed to overcome a "circular gap", as it enables to focus resources and management efforts on an increase concerning a small group of indicators, which contribute most to the uneven development of a circular economy by countries.

The annual "roadmaps" to overcome "circular gaps" can be developed on this basis. In fact, these selected indicators, included in IGF, are the drivers of circular economy development and competitiveness, as they determine leadership or outsidership positions of individual countries. Periodic assessment of the progress by these key indicators can be used as the indicator of the performance efficiency of the EU programs or actions of national governments. Moreover, the assessment of the significance of different indicators of circular economy is valuable to support for investments, small and medium-sized enterprises, labor market, various innovations, which facilitate the formation of such economy, as well as the reformation of industrial zones and infrastructure.

The outcomes of the third stage are the parametric characteristics of the level of uneven progress of the EU countries to a circular economy 
by the identified indicators, which are recognized as key factors. It can be used in the development of supranational policy, including as a basis for setting the strategic target indicators, which should be achieved by the countries, or criteria for providing support by the EU countries. In addition to clustering, such parametric analysis also enables to take decisions in respect of cooperation between the EU countries in the sphere of a circular economy.

In general, it can be used as a basis for 1) development of measures for the transition of the countries-outsiders towards a circular economy, focusing on the particular key indicators; 2) establishment of mechanisms for international cooperation to overcome "circular gap", focus- ing on specific areas, determined based on the identified factors of unevenness; 3) justifying the requirements, principles, and methodologies to manage the progress towards a circular economy at the level of the EU countries using the differentiated approach and assessment of the appropriate measures; 4) improvement of the system of statistic monitoring of circular economy in the EU countries, focusing on the synchronicity in implementing the strategy of sustainable development. The issues of the progress towards circular economy fall into different areas of the EU economic policies related to promoting investments, innovations, performance efficiency, and boosting employment. In this context, the parametric analysis also enables the adjustment of relevant indicators.

\section{CONCLUSION}

This study was aimed to identify the factors of the uneven progress of the EU countries towards a circular economy based on the analysis of empirical data, and Data Mining methods were used for that purpose. The analysis was carried out in three stages. At the first stage, including 20 indicators of circular economy, the clustering of the EU countries was carried out and three clusters were obtained, which characterize the level of the progress made by such countries towards this economy, i.e., leaders, followers, and outsiders were identified. By the results of the second stage, namely, the classification of the obtained clusters (classes) of the EU countries, two combinations of indicators were identified, which make all these clusters different. Having summarized all these combinations, the group of six indicators was obtained, which, by their nature, are interpreted as the factors of uneven progress of the EU countries towards circular economy during this period. At the third stage, the parametric analysis of the indicators of the obtained group was carried out; in particular, maximum, harmonious mean, and minimum values by each cluster of the EU countries were calculated. It enabled to qualitatively demonstrate the level of the uneven progress made by the EU countries towards a circular economy by clusters. The calculated difference between harmonic means for each of six factors of unevenness became an assessment of a "circular gap" between the clusters of the EU countries (according to the relevant indicators). Therefore, it provides an insight into the "landscape" of circular economy development in the EU as well as positions of individual member countries. The identified factors of the uneven progress made by countries towards such an economy should be considered as a priority for the strengthening to overcome a "circular gap" that the national and supranational policies can be focused on. Further studies are expected to assess the synchronicity in implementing a common strategy of sustainable development by the EU countries, which is of interest not only to the EU countries but also to partner countries.

\section{AUTHOR CONTRIBUTIONS}

Conceptualization: Maxim Polyakov, Igor Khanin, Vladimir Bilozubenko, Maxim Korneyev.

Data curation: Vladimir Bilozubenko, Gennadij Shevchenko.

Formal analysis: Vladimir Bilozubenko, Maxim Korneyev, Gennadij Shevchenko.

Investigation: Maxim Polyakov, Igor Khanin, Vladimir Bilozubenko, Maxim Korneyev, Gennadij

Shevchenko.

Methodology: Maxim Polyakov, Vladimir Bilozubenko, Maxim Korneyev, Gennadij Shevchenko. 
Project administration: Maxim Polyakov, Vladimir Bilozubenko.

Supervision: Maxim Polyakov, Igor Khanin, Vladimir Bilozubenko, Maxim Korneyev, Gennadij

Shevchenko.

Validation: Gennadij Shevchenko.

Writing - original draft: Maxim Polyakov, Igor Khanin, Vladimir Bilozubenko, Maxim Korneyev,

Gennadij Shevchenko.

Writing - review \& editing: Maxim Polyakov, Igor Khanin, Vladimir Bilozubenko, Gennadij

Shevchenko.

\section{REFERENCES}

1. Androniceanu, A., Kinnunen, J., \& Georgescu, I. (2021). Circular economy as a strategic option to promote sustainable economic growth and effective human development. Journal of International Studies, 14(1), 60-73. http://doi. org/10.14254/2071-8330.2021/14$1 / 4$

2. Barros, M.V., Salvador, R., Do Prado, G.F., De Francisco, A.C., \& Piekarski, C.M. (2021). Circular economy as a driver to sustainable businesses. Cleaner Environmental Systems, 2, 100006. https://doi. org/10.1016/j.cesys.2020.100006

3. Bassi, F., \& Dias, J.G. (2019). The use of circular economy practices in SMEs across the EU. Resources, Conservation and Recycling, 146, 523-533. https://doi.org/10.1016/j. resconrec.2019.03.019

4. Domenech, T., \& Bahn-Walkowiak, B. (2019). Transition towards a Resource Efficient Circular Economy in Europe: Policy Lessons from the EU and the Member States. Ecological Economics, 155, 7-19. https://doi.org/10.1016/j.ecolecon.2017.11.001

5. Enyoghasi, C., \& Badurdeen, F. (2021). Industry 4.0 for sustainable manufacturing: Opportunities at the product, process, and system levels. Resources, Conservation and Recycling, 166, 105362. https://doi.org/10.1016/j.resconrec.2020.105362

6. Eurostat Database (2021). Circular economy indicators. Eurostat. Retrieved from https://ec.europa.eu/ eurostat/data/database

7. Everitt, B., Landau, S., Leese, M., \& Stahl, D. (2011). Cluster Analysis. John Wiley \& Sons Ltd.
8. Fidélis, T., Cardoso, A.S., Riazi, F., Miranda, A.C., Abrantes, J., Teles, F., \& Roebeling, P.C. (2021). Policy narratives of circular economy in the EU - Assessing the embeddedness of water and land in national action plans. Journal of Cleaner Production, 288, 125685. https://doi.org/10.1016/j. jclepro.2020.125685

9. Friant, M.C., Vermeulen, W.J.V., \& Salomone, R. (2021). Analysing European Union circular economy policies: words versus actions. Sustainable Production and Consumption, 27, 337-353. https://doi. org/10.1016/j.spc.2020.11.001

10. Geissdoerfer, M., Pieroni, M.P., Pigosso, D.C., \& Soufani, K. (2020). Circular business models A review. Journal of Cleaner Production, 277, 123741. https://doi. org/10.1016/j.jclepro.2020.123741

11. Geissdoerfer, M., Savaget, P., Bocken, N.M.P., \& Hultink, E.J. (2017). The Circular Economy - A new sustainability paradigm? Journal of Cleaner Production, 143, 757-768. https://doi.org/10.1016/j. jclepro.2016.12.048

12. Grafström, J., \& Aasma, S. (2021). Breaking circular economy barriers. Journal of Cleaner Production, 292, 126002. https://doi. org/10.1016/j.jclepro.2021.126002

13. Hartley, K., Van Santen, R., \& Kirchherr, J. (2020). Policies for transitioning towards a circular economy: Expectations from the European Union (EU). Resources, Conservation and Recycling, 155, 104634. https://doi.org/10.1016/j. resconrec.2019.104634

14. Hughes, R. (2017). The EU Circular Economy Package - Life Cycle
Thinking to Life Cycle Law? Procedia CIRP, 61, 10-16. https://doi. org/10.1016/j.procir.2016.12.006

15. Hysa, E., Kruja, A., Rehman, N.U., \& Laurenti, R. (2020). Circular Economy Innovation and Environmental Sustainability Impact on Economic Growth: An Integrated Model for Sustainable Development. Sustainability, 12(12), 4831. https://doi.org/10.3390/ su12124831

16. Iacovidou, E., \& Gerassimidou, S. (2018). Sustainable Packaging and the Circular Economy: An EU Perspective. Reference Module in Food Science. https://doi. org/10.1016/B978-0-08-100596$5.22488-8$

17. Kern, F., Sharp, H., \& Hachmann, S. (2020). Governing the second deep transition towards a circular economy: How rules emerge, align and diffuse. Environmental Innovation and Societal Transitions, 37, 171-186. https://doi.org/10.1016/j. eist.2020.08.008

18. Kirchherr, J., Piscicelli, L., Bour, R., Kostense-Smit, E., Muller, J., Huibrechtse-Truijens, A., \& Hekkert, M. (2018). Barriers to the Circular Economy: Evidence from the European Union (EU). Ecological Economics, 150, 264272. https://doi.org/10.1016/j. ecolecon.2018.04.028

19. Korhonen, J., Honkasalo, A., \& Seppälä, J. (2018a). Circular Economy: The Concept and its Limitations. Ecological Economics, 143, 37-46. https://doi.org/10.1016/j. ecolecon.2017.06.041

20. Korhonen, J., Nuur, C., Feldmann, A., \& Birkie, S. E. (2018b). Circular economy as an essen- 
tially contested concept. Journal of Cleaner Production, 175, 544552. https://doi.org/10.1016/j. jclepro.2017.12.111

21. Krysovatyy, A., Zvarych, I., \& Zvarych, R. (2018). Circular economy in the context of alterglobalization. Journal of International Studies, 11(4), 185-200. https://doi. org/10.14254/2071-8330.2018/11$4 / 13$

22. Lazarevic, D., \& Valve, H. (2017). Narrating expectations for the circular economy: Towards a common and contested European transition. Energy Research \& Social Science, 31, 60-69. https://doi. org/10.1016/j.erss.2017.05.006

23. Marino, A., \& Pariso, P. (2020). Comparing European countries' performances in the transition towards the Circular Economy. Science of The Total Environment, 729, 138142. https://doi.org/10.1016/j. scitotenv.2020.138142.

24. Martins, F., \& Castro, H. (2019). Significance ranking method applied to some EU critical raw materials in a circular economy - priorities for achieving sustainability. Procedia CIRP, 84, 10591062. https://doi.org/10.1016/j. procir.2019.04.281

25. Matthews, C., Moran, F., \& Jaiswal, A.K. (2021). A review on European Union's strategy for plastics in a circular economy and its impact on food safety. Journal of Cleaner Production, 283, 125263. https://doi.org/10.1016/j. jclepro.2020.125263

26. McDowall, W., \& Geng, Y. (2017). Circular economy policies in China and Europe. Journal of Industrial Ecology, 21(3), 651-661. https://doi.org/10.1111/jiec.12597

27. Momete, D.C. (2020). A unified framework for assessing the readiness of European Union economies to migrate to a circular modelling. Science of The Total Environment, 718, 137375. https://doi.org/10.1016/j.scitotenv.2020.137375

28. Pakurár, M., Khan, M.A., Benedek, A., \& Oláh, J. (2020). The impact of green practices, cooperation and innovation on the performance of supply chains using statistical method of metaanalysis. Journal of International Studies, 13(3), 111-128. https://doi. org/10.14254/2071-8330.2020/13$3 / 8$

29. Peiró, L.T., Polverini, D., Ardente, F., \& Mathieux, F. (2020). Advances towards circular economy policies in the EU: The new Ecodesign regulation of enterprise servers. Resources, Conservation and Recycling, 154, 104426. https://doi.org/10.1016/j.resconrec.2019.104426

30. Ranta, V., Aarikka-Stenroos, L., Ritala, P., \& Mäkinen, S.J. (2018). Exploring institutional drivers and barriers of the circular economy: A cross-regional comparison of China, the US, and Europe. Resources, Conservation and Recycling, 135, 70-82. https://doi.org/10.1016/j.resconrec.2017.08.017

31. Schot, J., \& Kanger, L. (2018). Deep Transitions: Emergence, Acceleration, Stabilization and Directionality. Research Policy, 47(6), 1045-1059. https://doi. org/10.1016/j.respol.2018.03.009

32. Schroeder, P., Anggraeni, K., \& Weber, U. (2018). The relevance of circular economy practices to the Sustainable Development Goals. Journal of Industrial Ecology, 23(9), 77-95. https://doi.org/10.1111/ jiec. 12732

33. ScienceHunter. (n.d.). Main page. (In Russian). Retrieved from https://www.sciencehunter.net/

34. United Nations Environment. (2011). Towards a green economy: Pathways to sustainable development and poverty eradication. Nairobi, Kenya. Retrieved from https:// sustainabledevelopment.un.org/ index.php?page $=$ view $\&$ type $=400 \&$ $\mathrm{nr}=126 \&$ menu $=35$

35. Valenzuela, F., \& Böhm, S. (2017). Against wasted politics: a critique of the circular economy. Ephemera: Theory \& Politics in Organization, 17(1), 23-60. Retrieved from http:// www.ephemerajournal.org/contribution/against-wasted-politicscritique-circular-economy

36. Vasylenko, Y.A., \& Shevchenko, H.Y. (1979). Analytical Method for Test Finding. Avtomatyka, 2, 3-8.

37. Velenturf, A.P.M., \& Purnell, P. (2021). Principles for a Sustainable Circular Economy. Sustainable Production and Consumption, 27, 1437-1457. https://doi. org/10.1016/j.spc.2021.02.018

38. Velenturf, P. M., Purnell, P., Macaskie, L. E., Mayes, W. M., \& Sapsford, D. J. (2019). A New Perspective on a Global Circular Economy. In L.E. Macaskie, D.J. Sapsford \& W.M. Mayes (Eds.), Resource Recovery from Wastes: Towards a Circular Economy (pp. 1-22). Royal Society of Chemistry. https://doi. org/10.1039/978178801635300001

39. Zielińska, A. (2019). Comparative Analysis of Circular Economy Implementation in Poland and other European Union Countries. Journal of International Studies, 12(4), 337-347. https://doi. org/10.14254/2071-8330.2019/12$4 / 22$ 